Journal of Physical Science, Vol. 29(Supp. 2), 15-26, 2018

\title{
Wear Analysis of Spherical Graphite Cast Iron Using Pin-on Disc Tribotester
}

\author{
Muchammad, ${ }^{1 *}$ Imam Syafa' at, ${ }^{2}$ Fuad Hilmy, ${ }^{1}$ Mohammad Tauviqirrahman ${ }^{1}$ and Jamari ${ }^{1}$ \\ ${ }^{1}$ Department of Mechanical Engineering, Engineering Faculty, Universitas Diponegoro, \\ Semarang 50275, Indonesia \\ ${ }^{2}$ Department of Mechanical Engineering, Engineering Faculty, \\ Universitas Wahid Hasyim, Semarang 50236, Indonesia \\ *Corresponding author: m_mad5373@yahoo.com
}

Published online: 30 July 2018

To cite this article: Muchammad et al. (2018). Wear analysis of spherical graphite cast iron using pin-on disc tribotester. J. Phys. Sci., 29(Supp. 2), 15-26, https://doi.org/10.21315/ jps2018.29.s2.2

To link to this article: https://doi.org/10.21315/jps2018.29.s2.2

\begin{abstract}
Cast iron is widely used due to low price, good machining and good damping capability. However, it has huge friction. In certain automotive components such as cylindrical liner, cast iron is used. The biggest challenge in cylinder liner is obtaining lower friction and wear. The main aim of the paper is to experimentally investigate the characteristics of wear induced by the sliding contact piston ring cylinder liner without lubrication. The modified material of spherical graphite cast iron has been explored. The indenter load, hardness and wear are of main particular interest. The pin on disk tribotester is used to obtain the characteristics of wear volume, wear width and wear depth. The other purpose of this research is to observe the characteristics of cylinder liner wear of spheroidal graphite cast iron from Klaten, Indonesia. The results show that low indenter load causes wear depth and volume. This finding is in a good agreement with published works. In addition, it is found that the material hardness also greatly affects the wear depth, wear volume and wear width.
\end{abstract}

Keywords: Cast iron, pin on disc, spherical graphite, tribotester, wear

\section{INTRODUCTION}

Today, performance requirement of spheroidal graphite cast iron in automotive component is becoming increasingly demanding. Cast iron graphite is used in the manufacturing and automotive components such as arms, sprockets and tool

(C) Penerbit Universiti Sains Malaysia, 2018. This work is licensed under the terms of the Creative Commons Attribution (CC BY) (http://creativecommons.org/licenses/by/4.0/). 
holders, whereas spherical graphite cast iron is utilised in the automotive field such as camshafts, crankshafts and gears. In many of the studies published, the wear is often of particular interest. Wear is the loss of parts due to the interaction occurring during motion of two surfaces. ${ }^{1}$

A great challenge in the development of cylinder liner piston ring contact is in obtaining optimal tribological performance of the moving parts. This is because the lubricant behaviour is different on micro- or nano-scale compared to macroscale. On micro- or nano-scale, the boundary condition plays a significant role in determining the lubricant flow behaviour between the interacting components. The control of the boundary condition will allow a degree of verification over the hydrodynamic pressure in confined systems and is important in lubricated-contact.

Recently, studies have proven that the automotive contact can be beneficial. For example, the contact in slider bearing has been explored by Muchammad et al., which found that the contact in certain cases can enhance the hydrodynamic pressure locally, resulting in a higher load carrying capacity. ${ }^{2}$ Other researchers also explored tribological automotive components. One of them focused on wear and coefficient of friction on cylinder liner piston ring on the gray cast iron materials. ${ }^{3}$ The results showed that the steady-state wear rate was lower for the piston ring which has the cylinder liner. Aaron et al. studied the tribological performance of a flat piston ring prototype with partially textured surface by experimental method. ${ }^{4}$ The material of the piston ring was low carbon steel while the cylinder liner was made of cast iron. The results indicated that the ratio and optimal texture depth have a significant effect on the tribological behaviour and the reduction of friction. Pettavino et al. demonstrated that the theoretical model of the piston ring cylinder liner contact fully flooded lubrication with textured surfaces. ${ }^{5}$ The flat part of the geometry can be caused either by design or wear. Alternatively, design optimisation can require a combination of a parabolic and a flat geometry.

Based on simulation, $\mathrm{Gu}$ et al. found that the textured liner can result in considerable benefits on the tribological properties. ${ }^{6}$ However, the positive influence of the textured ring may remain unsteady under starved lubrication. Experimentally, Söderfjäll et al. reported that the piston ring cylinder liner contact largely contributes to mechanical friction losses in internal combustion engines. ${ }^{7}$ It is therefore important to have methods and tools available to investigate these frictional losses. It has been found that the oil control ring is significantly affected by the contact with the spring loading against the cylinder liner. As a consequence, the friction is also affected by such contact in special condition; in this case, the spring sticks on the back of the rings. 
The main aim of the paper is to experimentally investigate the characteristics of wear induced by the sliding contact piston ring cylinder liner without lubrication. Different materials of spherical graphite cast iron have been explored. The main particular interest is to study the impact of material hardness with respect to wear depth and wear volume. The other purpose of this research is to observe the characteristics of cylinder liner wear of spheroidal graphite cast iron from Klaten, Indonesia. The finding of the present research can facilitate assessing the potential application of spheroidal graphite cast iron with chrome content in cylinder liner.

\section{EXPERIMENTAL}

In this study, the pin-on disc tribotester is utilised, and graphite spherical cast iron is used as the material. Three models of graphite spherical cast iron hardness are proposed: Ferro Casting Ductile (FCD) 40, FCD 50 and FCD 60. The indenter's material used is Strength Tensile (ST) 60 and adjustable pin size was used. The tribotester specifications used in this study are presented in Table 1. The composition of FCD material is $3.4 \% \mathrm{C}, 1.5 \% \mathrm{Si}, 0.6 \% \mathrm{Mn}$ and the remaining is Fe. FCD 40 contains additional $0.01 \% \mathrm{Mg}$ and $0.01 \% \mathrm{Cr}$. For FCD 50 contains $0.02 \% \mathrm{Mg}$ and $0.02 \% \mathrm{Cr}$. Compositions of $0.03 \% \mathrm{Mg}$ and $0.03 \% \mathrm{Cr}$ were added into FCD 60 . As is known, $\mathrm{Mg}$ and $\mathrm{Cr}$ have the ability to improve the basic material.

Table 1: Specification of tribotester pin on disc.

\begin{tabular}{lll}
\hline No & Property & Value \\
\hline 1 & Movers & Electric motor 3 phase $1 / 2 \mathrm{HP}$ \\
2 & Weights & $1 \mathrm{~kg}$ \\
3 & Inventer & Brand INVT, GD 10 max capacity $1 \mathrm{HP}$ \\
\hline
\end{tabular}

The tribotester pin-on disk is shown in Figure 1. It includes a description of the component material of tribotester. The specifications of the component are shown in Table 2. The test material is rotated by electric motor and the indenter is stationary with external load. Sliding distance is recorded and varied. Rotation electric motor is controlled by inverter. 


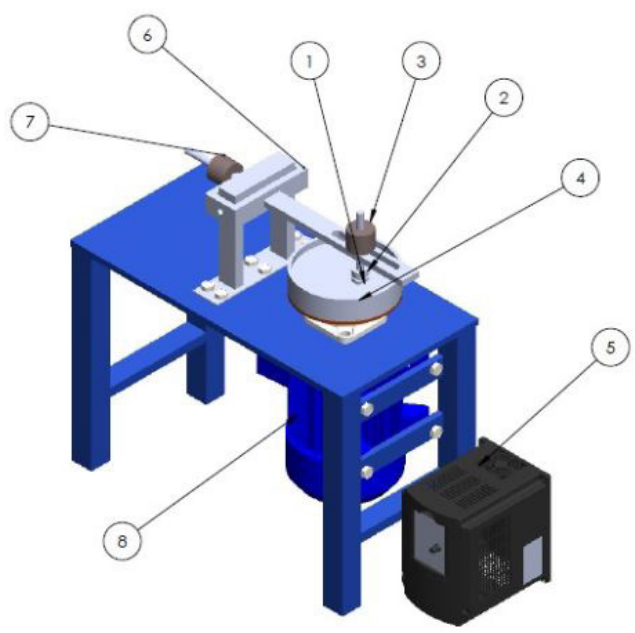

Figure 1: Tribotester pin-on disc.

Table 2: Main component of tribotester pin-on disc.

\begin{tabular}{lll}
\hline No & Name of part & Function \\
\hline 1 & Pin & Wear test \\
2 & Holder & Pin holder \\
3 & External load & Load regulator \\
4 & Disc material & Wear test \\
5 & Inverter & Electric motor control \\
6 & Load arms & Connecting external load and balancer \\
7 & Load balancer & Balancing the load \\
8 & Electric motor & Rotating disc \\
\hline
\end{tabular}

The material samples are tested with Rockwell hardness tester. The hardness test uses Brinell method (i.e., FCD 40, FCD 50 and FCD 60) to determine the hardness of disc. The material used is spherical graphite cast iron with varying contents of chrome.

Pin-on disc tribotester is used to determine the wear depth and wear volume. External load is set to $1 \mathrm{~kg}$ and sliding distance is varied at $200 \mathrm{~m}, 300 \mathrm{~m}$ and $500 \mathrm{~m}$. Wear depth is analysed with scanning electron microscope (SEM) and wear volume is calculated using the Archard, Sarkar, and Kauzlarich and Williams formulae. The variation of disk used is classified into three models: disc with cast iron material A (FCD 40); disc with cast iron material B (FCD 50); and disc with cast iron material C (FCD 60). 


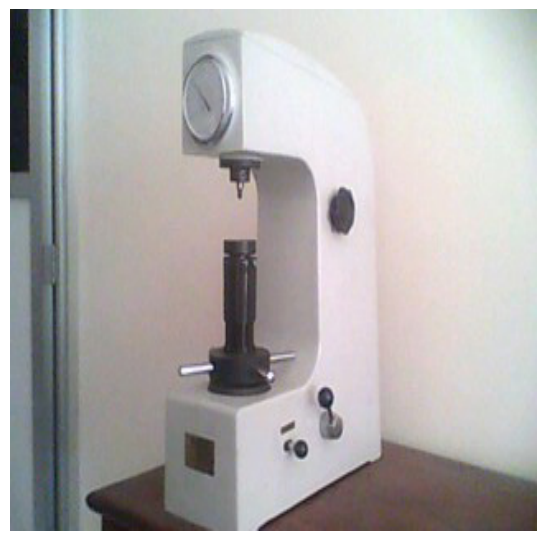

Figure 2: Rockwell hardness tester.

The wear volume is calculated with Equation 1:

$$
V=\frac{\pi}{6} d \frac{\left(W^{3}\right)}{R}
$$

where $V$ is wear volume, $W$ is track of wear width on the disc, $d$ is the radius of wear, and $R$ is the ball radius indenter.

In the present study, the wear volume is also calculated using other equations. Figure 2 shows the comparison of the present model with Archard, Sarkar et al., and Kauzlarich and Williams models. ${ }^{8-10}$ Equations 2 to 4 describe these models, with an addition of Stachowiak model shown in Equation 5. ${ }^{11}$

$$
\begin{aligned}
& V=k_{D} \cdot F_{N} \cdot s \\
& \frac{V}{s}=k \frac{F_{N}}{H} \sqrt{1+3 \mu^{2}} \\
& \frac{V}{R^{3}}=\pi K_{D} p N \\
& V=\frac{\pi h}{6}\left[\frac{3}{4} d^{2}+h^{2}\right]
\end{aligned}
$$


For these equations, $V$ is wear volume, $F_{N}$ is representation of normal load, $s$ is sliding distance, $H$ is hardness material, $k$ is dimensionless wear coefficient, $\mu$ is friction coefficient, $p$ is pressure contanct, $N$ is number of revolution, and $h$ is wear depth.

\section{RESULTS AND DISCUSSION}

\subsection{Wear Width}

In this work, the first investigation deals with the effect of wear. It can be seen from Figure 1 that the sliding distance of $200 \mathrm{~m}, 300 \mathrm{~m}$ and $500 \mathrm{~m}$ affected the wear width. In the case of disc A (FCD 40 with hardness $79.5 \mathrm{HRB}$ and external load $10 \mathrm{~N}$ ), it can be observed that increase in sliding distance increases the wear effect. At a sliding distance of $200 \mathrm{~m}$, the wear width is $0.6723 \mu \mathrm{m}$, which increases linearly with increasing sliding distance. These conditions also occur in other materials, but the harder materials will reduce the effect of wear. Detailed data of wear width is tabulated in Table 3. It shows the considerable effect of material hardness and sliding distance on the wear width. From Table 3, it can be seen that disc $\mathrm{C}$ has smallest wear width due to higher value of hardness.

In the case of disc B (FCD 50 with hardness $82 \mathrm{HRB}$ and external load $10 \mathrm{~N}$ ), it is found that the wear width also increases linearly with the increasing sliding distance. However, the wear width is still smaller compared to disc A under the same conditions. Disc C (FCD 60 at hardness 86.5 HRB and external load $10 \mathrm{~N}$ ) has the best specification in terms of hardness, with smaller wear width. It can be concluded that hardness influences the reduction of wear. 


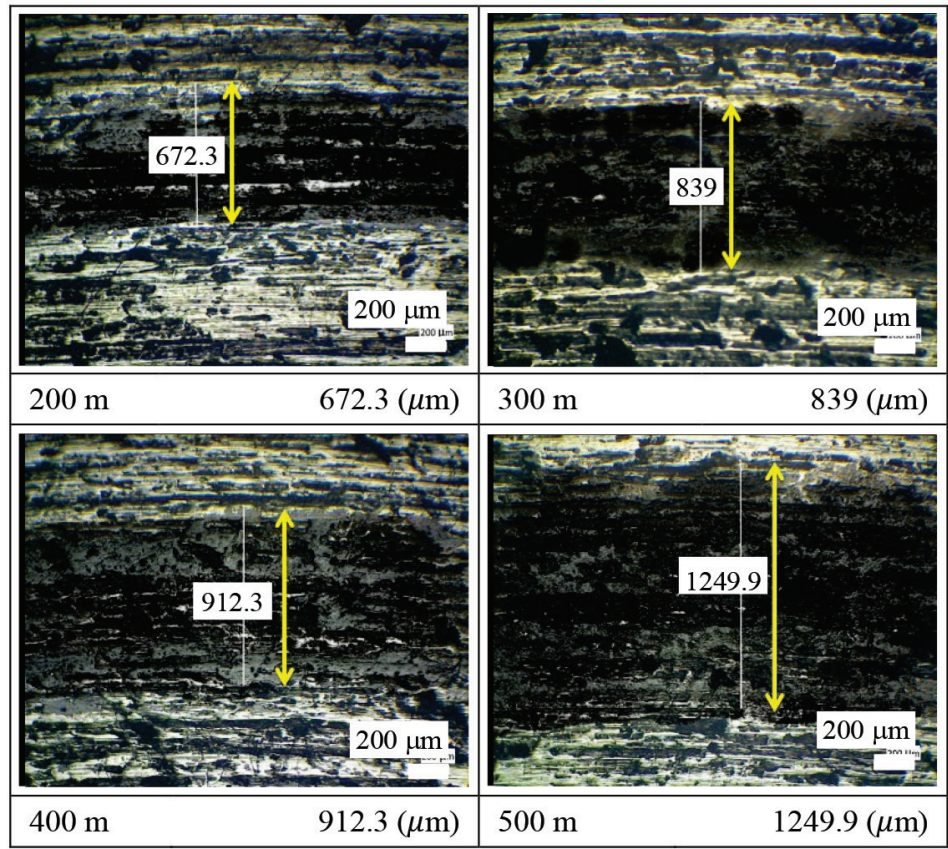

Figure 3: Effect of the sliding distance on the wear width for material A.

Table 3: Effect of sliding distance and type of materials on wear width.

\begin{tabular}{lcc}
\hline Materials & Sliding distance $(\mathrm{m})$ & Wear width $(\mathrm{mm})$ \\
\hline & 200 & 0.672 \\
Disc A & 300 & 0.839 \\
FCD 40 & 400 & 0.913 \\
& 500 & 1.249 \\
\hline & 200 & 0.640 \\
Disc B & 300 & 0.792 \\
FCD 50 & 400 & 0.891 \\
& 500 & 1.170 \\
\hline & 200 & 0.618 \\
Disc C & 300 & 0.667 \\
FCD 60 & 400 & 0.778 \\
& 500 & 0.896 \\
\hline
\end{tabular}




\subsection{Wear Volume}

Based on Equation 1, the wear width on the disc is configured to obtain the wear volume. The results of the calculation of the wear width and wear volume of the experiment can be seen in Table 4.

Table 4: Effect of sliding distance and type of materials on wear volume.

\begin{tabular}{|c|c|c|c|c|c|}
\hline No & Disc & $\begin{array}{l}\text { Roughness } \\
\text { (HRB) }\end{array}$ & $\begin{array}{l}\text { Sliding distance } \\
(\mathrm{m})\end{array}$ & $\begin{array}{l}\text { Wear width } \\
\quad(\mathrm{mm})\end{array}$ & $\begin{array}{l}\text { Wear volume } \\
\qquad\left(\mathrm{mm}^{3}\right)\end{array}$ \\
\hline \multirow{4}{*}{1} & \multirow{4}{*}{$\begin{array}{l}\text { Disc A } \\
\text { FCD } 40\end{array}$} & \multirow{4}{*}{79.5} & 200 & 0.672 & 1.671 \\
\hline & & & 300 & 0.839 & 2.056 \\
\hline & & & 400 & 0.913 & 3.097 \\
\hline & & & 500 & 1.249 & 9.100 \\
\hline \multirow{4}{*}{2} & \multirow{4}{*}{$\begin{array}{l}\text { Disc B } \\
\text { FCD } 50\end{array}$} & \multirow{4}{*}{82} & 200 & 0.640 & 1.189 \\
\hline & & & 300 & 0.792 & 1.610 \\
\hline & & & 400 & 0.891 & 2.656 \\
\hline & & & 500 & 1.170 & 6.804 \\
\hline \multirow{4}{*}{3} & \multirow{4}{*}{$\begin{array}{l}\text { Disc C } \\
\text { FCD } 60\end{array}$} & \multirow{4}{*}{86.5} & 200 & 0.618 & 0.781 \\
\hline & & & 300 & 0.667 & 1.366 \\
\hline & & & 400 & 0.778 & 2.472 \\
\hline & & & 500 & 0.896 & 5.865 \\
\hline
\end{tabular}

In addition to the experimental calculations, the wear volume is also calculated based on the geometry and wear volumes as described in the Archard model. Figure 4 shows the effect of sliding distance on the wear volume. Wear volume increases with increasing sliding distance and decreasing material hardness. The experimental result matches well with Archard, Sarkar, and Kauzlarich and Williams models in small sliding distance. The sliding distance of $500 \mathrm{~m}$ has different wear volume compared with other studies. This is because the flake of wear of the FCD material contributes in increasing the wear volume during the sliding process, which has not been taken into consideration in the previous models. FCD 60 has the greatest hardness and the experimental results show the smallest wear volume. The addition of $\mathrm{Mg}$ and $\mathrm{Cr}$ directly affects the wear volume. This phenomenon is accordance with the initial hypothesis that the cylinder liner material must be resistant to wear. 


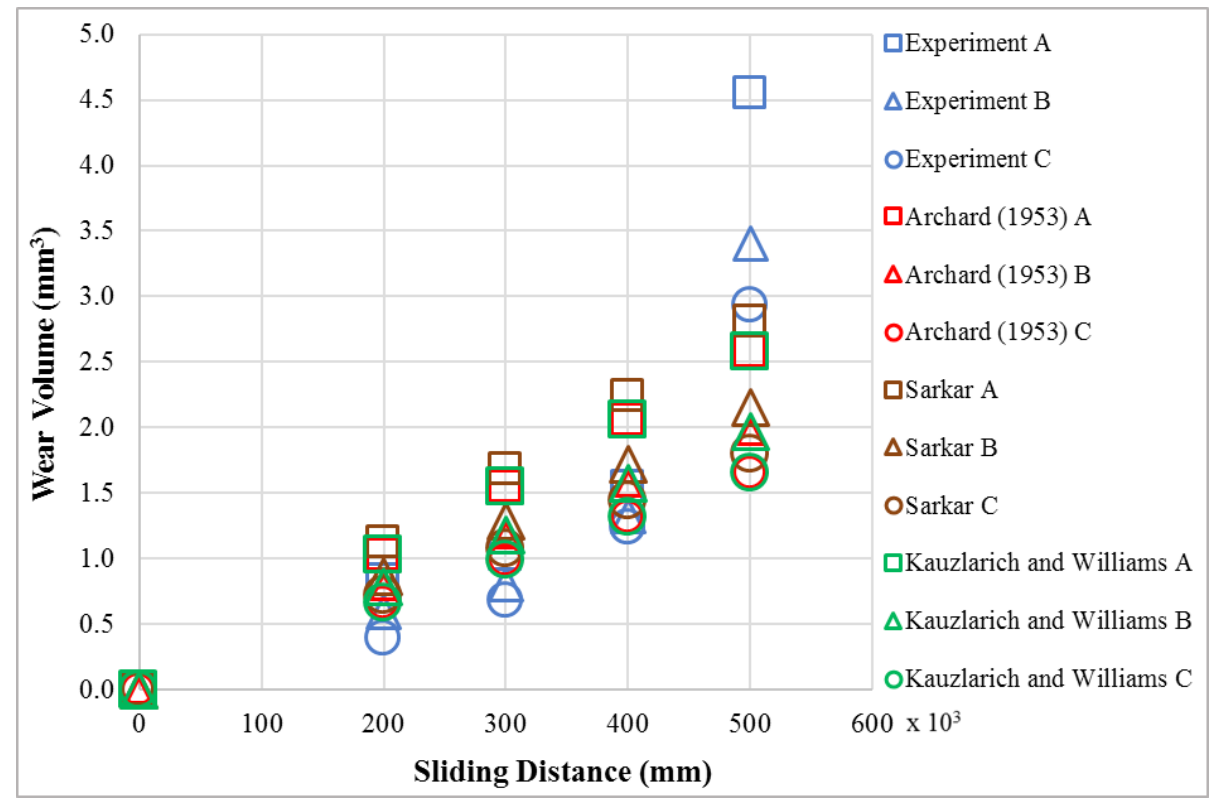

Figure 4: Effect of the sliding distance on the wear volume.

\subsection{Wear Depth}

By using simple Pythagoras, the wear width is configured to obtain wear depth, and then it is used to get the experimental volume. The wear depth obtained from the experimental can be seen in Table 5. The results show that wear depth is linier with the wear width and sliding distance. The wear depth decreases with increasing material hardness.

Based on Figure 5, it can be observed that the experimental wear depth has been compared with Archard, Sarkar, and Kauzlarich and Williams models. The present result is in a good agreement with other researchers in all sliding distance values. For example, at a sliding distance of $500 \mathrm{~m}$, the wear depth by the work of Sarkar, and Kauzlarich and Williams is $0.041 \mathrm{~mm}$. This value is close to the experimental data. This observation is consistent with the initial prediction that the hardness of the material will decrease wear depth. Comparing with other models is useful to predict the accuracy of the experimental results. The experimental results show that the wear depth value matches well with the other models. 
Table 5: Wear depth based on experimental method.

\begin{tabular}{|c|c|c|c|c|c|}
\hline No & Disc & $\begin{array}{l}\text { Roughness } \\
\text { (HRB) }\end{array}$ & $\begin{array}{l}\text { Sliding distance } \\
(\mathrm{m})\end{array}$ & $\begin{array}{l}\text { Wear width } \\
\quad(\mathrm{mm})\end{array}$ & $\begin{array}{c}\text { Wear depth } \\
(\mathrm{mm})\end{array}$ \\
\hline \multirow{4}{*}{1} & \multirow{4}{*}{$\begin{array}{l}\text { Disc A } \\
\text { FCD } 40\end{array}$} & \multirow{4}{*}{79.5} & 200 & 0.672 & 0.012 \\
\hline & & & 300 & 0.839 & 0.019 \\
\hline & & & 400 & 0.913 & 0.022 \\
\hline & & & 500 & 1.249 & 0.041 \\
\hline \multirow{4}{*}{2} & \multirow{4}{*}{$\begin{array}{l}\text { Disc B } \\
\text { FCD } 50\end{array}$} & \multirow{4}{*}{82} & 200 & 0.640 & 0.010 \\
\hline & & & 300 & 0.792 & 0.016 \\
\hline & & & 400 & 0.891 & 0.021 \\
\hline & & & 500 & 1.170 & 0.036 \\
\hline \multirow{4}{*}{3} & \multirow{4}{*}{$\begin{array}{l}\text { Disc C } \\
\text { FCD } 60\end{array}$} & \multirow{4}{*}{86.5} & 200 & 0.618 & 0.010 \\
\hline & & & 300 & 0.667 & 0.012 \\
\hline & & & 400 & 0.778 & 0.016 \\
\hline & & & 500 & 0.896 & 0.021 \\
\hline
\end{tabular}

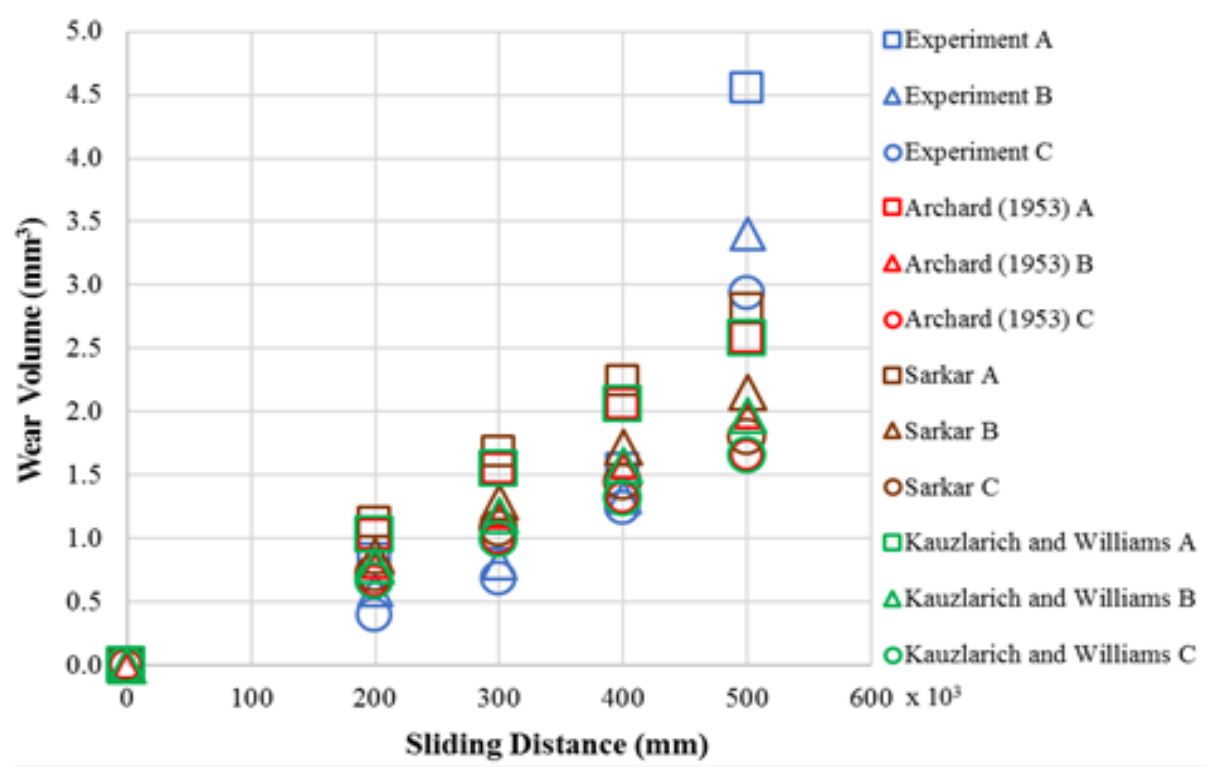

Figure 5: Effect of the sliding distance on the wear depth. 


\section{CONCLUSION}

In the present study, the effect of sliding distance and material hardness on wear depth, wear width and wear volume were analysed. The experimental method based on a pin disk tribotester was used. A few summaries can be made in this study. First, the material hardness greatly affects wear volume; the higher wear volume occurs on material FCD 40 and lower wear volume occurs on FCD 60. Second, increasing sliding distance increases the wear volume, wear depth and wear width.

\section{ACKNOWLEDGEMENTS}

This research is fully supported by the Riset Pengembangan dan Penerapan or Development and Application Research (RPP) grant, no. 275-104/UN7.5.1/ PG/2017. The authors fully acknowledge Universitas Diponegoro, Indonesia for the approved fund which makes this important research viable and effective.

\section{REFERENCES}

1. Ali, S. H. R., Mohamed, H. H. \& Kama, M. (2009). Identifying cylinder liner wear using precise coordinate measurements. Int. J. Precis. Eng. Man., 10(5), 19-25, https://doi.org/10.1007/s12541-009-0088-y.

2. Muchammad, M. et al. (2017). An analytical approach on the tribological behaviour of pocketed slider bearings with boundary slip including cavitation. Lubr. Sci., 29(3), 133-152, https://doi.org/ 10.1002/1s.1361.

3. Shen, Y. et al. (2017). Comparison of heavy-duty scuffing behavior between chromium-based ceramic composite and nickel-chromium-molybdenumcoated ring sliding against cast iron liner under starvation. Mater., 10(10), 1176, https://doi.org/ 10.3390/ma10101176.

4. Ashwin, A. M. \& Sashidhar, A. (2012). Frictional power minimization in partially textured piston ring assembly. Int. J. Mech. Indust. Eng., 2(4), 40-44.

5. Pettavino, C., Biboulet, N. \& Lubrecht, A. A. (2016). Load carrying capacity and friction of a parabolic-flat piston ring of finite width. Tribol. Int., 100, 99-103, https://doi.org/ 10.1016/j.triboint.2015.11.043.

6. Gu, C. et al. (2016). Effects of surface texturing on ring/liner friction under starved lubrication. Tribol. Int., 94, 591-605, https://doi.org/ 10.1016/j. triboint.2015.10.024. 
7. Söderfjäll, M., Almqvist, A. \& Larsson, R. (2016). Component test for simulation of piston ring - Cylinder liner friction at realistic speeds. Tribol. Int., 104, 57-63, https://doi.org/ 10.1016/j.triboint.2016.08.021.

8. Archard, J. (1953). Contact and rubbing of flat surfaces. J. Appl. Phys., 24(8), 981-988, https://doi.org/ 10.1063/1.1721448.

9. Sarkar, A. D. (1980). Friction and wear. London: Academic Press.

10. Kauzlarich, J. J. \& Williams, J. A. (2001). Archard wear and component geometry. Proc. Inst. Mech. Eng. J. Eng. Tribol., 215(4), 387-403.

11. Stachowiak, G. W. (2006). Wear: Materials, mechanisms and practice. New York: John Wiley \& Sons. 